\title{
Estradiol Targets Synaptic Proteins to Induce Glutamatergic Synapse Formation in Cultured Hippocampal Neurons: Critical Role of Estrogen Receptor- $\alpha$
}

\author{
Karen Bozak Jelks, ${ }^{1}$ Rebecca Wylie, ${ }^{1}$ Candace L. Floyd, ${ }^{3}$ A. Kimberly McAllister, ${ }^{2}$ and Phyllis Wise ${ }^{4}$ \\ ${ }^{1}$ Department of Neurobiology, Physiology, and Behavior and ${ }^{2}$ Center for Neuroscience, University of California-Davis, Davis, California 95616-8536, \\ ${ }^{3}$ Department of Physical Medicine and Rehabilitation, University of Alabama-Birmingham, Birmingham, Alabama 35249-7330, and ${ }^{4}$ Department of \\ Physiology and Biophysics, University of Washington, Seattle, Washington 98195-1237
}

\begin{abstract}
Estradiol mediates structural changes at synapses of the hippocampus, an area in the brain important for learning and memory. This study was designed to test the hypothesis that estradiol mediates subcellular changes of synaptic proteins to induce new synapses via an estrogen receptor (ER)-mediated process. To elucidate the mechanisms involved in glutamatergic synapse formation, we investigated effects of estradiol on synaptic proteins in cultured hippocampal neurons using immunocytochemistry and confocal microscopy. Synaptic protein distribution and size were identified with antibodies to the presynaptic vesicular glutamate transporter protein (vGlut 1 ) and postsynaptic NMDA receptor (NR1 subunit). We observed an increase in synapse density, as detected by NR1 and vGlut1 colocalization, along dendrites of neurons cultured in steroid-stripped media and exposed to estradiol (10 nM) for $48 \mathrm{~h}$. Additionally, the NR1 subunit was enriched at synaptic clusters. Immunocytochemistry and confocal imaging revealed punctate staining of extranuclear ERs along dendrites of hippocampal neurons expressing NR1. Estradiol increased the density of both ER- $\alpha$ and ER- $\beta$ protein clusters along dendrites. To test whether ERs play an important functional role in the estradiol-induced synaptogenesis, we used the ER antagonist [7 $\alpha, 17 \beta$-[9[(4,4,5,5,5-pentafluoropentyl)sulfinyl]nonyl] estra-1,3,5(10)-triene-3,17-diol (ICI 182,780)] and the ER- $\alpha$ - and ER- $\beta$-specific agonists [1,3,5-tris(4-hydroxyphenyl)-4-propyl-1H-pyrazole (PPT) and 2,3-bis(4-hydroxyphenyl) propionitrile (DPN), respectively]. ICI 182,780 blocked the increase in synapse density. Treatment with PPT, but not DPN, induced significant increases in synapse density that mimicked treatment with estradiol. Together, our results demonstrate that estradiol stimulates glutamatergic synapse formation in the developing hippocampus through an ER- $\alpha$-dependent mechanism. These findings carry profound implications regarding the potential of estrogen to influence learning, memory, and possibly hormone-modulated neurodegeneration.
\end{abstract}

Key words: estradiol; glutamatergic synapse; hippocampus; subcellular localization; NMDA receptor; estrogen receptor

\section{Introduction}

Estrogens influence synaptogenesis and morphological plasticity within the brain, enhancing the density of dendritic spines (Gould et al., 1990; Woolley and McEwen, 1993) and subsequent synapse formation (Woolley and McEwen, 1992; Leranth et al., 2000) in the rat hippocampus. Cultured hippocampal neurons respond to estradiol as well (Murphy and Segal, 1996; PozzoMiller et al., 1999). Elucidating the mechanisms by which estradiol drives structural changes and modulates synaptic plasticity in the hippocampus will deepen our understanding of hippocampal-dependent learning and memory (Luine et al., 2003; Sandstrom and Williams, 2004). Furthermore, estradiol may influence hippocampal development and differentiation be-

Received June 6, 2006; revised May 4, 2007; accepted May 21, 2007.

This work was supported by National Institutes of Health (NIH) Grant P01 AG17164, National Institute of General Medical Sciences Grant K12 GM00679, NIH Grant AG02224, and the Ellison Medical Foundation. We thank Christina Craig-Veit for help with this manuscript.

Correspondence should be addressed to Dr. Phyllis Wise, Department of Physiology and Biophysics, University of Washington, Seattle, WA 98195-1237.E-mail: pmwise@u.washington.edu.

DOI:10.1523/JNEUROSCI.0909-07.2007

Copyright $\odot 2007$ Society for Neuroscience $\quad$ 0270-6474/07/276903-11\$15.00/0 cause extensive synaptogenesis occurs in the neonatal hippocampus (Fiala et al., 1998) during a developmental period when estradiol concentrations and estrogen receptor (ER) expression are particularly high (O'Keefe and Handa, 1990; Solum and Handa, 2001; Amateau et al., 2004).

A growing body of evidence suggests that estradiol impacts synaptic proteins. Estradiol elicits presynaptic changes, upregulating presynaptic proteins (Crispino et al., 1999; Choi et al., 2003; Prange-Kiel et al., 2006) and increasing the frequency of multiple synapse boutons in the CA1 region (Yankova et al., 2001). In addition, estrogen-induced synaptogenesis clearly depends on postsynaptic NMDA receptor (NMDAR) transmission because antagonists of NMDARs block estradiol-induced synaptogenesis in vivo (Weiland, 1992; Woolley and McEwen, 1994) and in vitro (Murphy and Segal, 1996). Recent studies report that membrane-bound ER activation regulates NMDAR phosphorylation in cortical synaptoneurosomes, demonstrating direct action of estradiol at synapses (Dominguez et al., 2007). Because NMDARs play a critical role in establishing appropriate synaptic connections in the developing brain (Cline et al., 1987), analyzing the impact of estradiol on NMDAR localization may begin to 
reveal how estradiol drives synaptogenesis and affects development.

Estradiol-induced increase in spines and synapses is mediated by activation of ERs (McEwen et al., 1999). ER- $\alpha$ and ER- $\beta$ have been found at extranuclear sites in the hippocampus (Milner et al., 2001, 2005) and cortex (Dubal et al., 2006). Their presence in dendritic spines and axons of hippocampal and cortical neurons (Clarke et al., 2000; Adams et al., 2002; Kalita et al., 2005; Romeo et al., 2005; Hu et al., 2007) suggests a role for the ER as a transducer of rapid, nongenomic estrogen-mediated events during synapse formation.

Here, we report the results of studies designed to analyze the effects of estradiol on axo-dendritic synaptogenesis between cultured hippocampal neurons using immunocytochemistry (ICC) and confocal microscopy. Although traditional techniques such as electron microscopy and electrophysiology are used to investigate synapses and their properties, this alternate technique using ICC and confocal microscopy to define synaptic sites where presynaptic and postsynaptic proteins colocalize (Glynn and McAllister, 2006) has allowed researchers to define regional, temporal, and developmental differences in synapse composition (Rao and Craig, 1997; Washbourne et al., 2002; Gomes et al., 2006). Here, we define a synapse strictly as colocalized presynaptic protein [vesicular glutamate transporter 1 (vGlut1)] and postsynaptic protein [NMDAR type 1 (NR1)] along dendrites. vGlut 1 is the primary vesicular glutamate transporter found on hippocampal neurons, and NR1 is an obligate subunit of the NMDAR. Colocalization of these proteins is likely to label even the youngest glultamatergic synapses because NMDARs are one of the first postsynaptic proteins to be recruited to nascent synapses within minutes of axo-dendritic contact (Washbourne et al., 2002).

We demonstrate that estradiol exposure significantly increases synapse density along dendrites. In addition, extranuclear ER expression (both $\alpha$ and $\beta$ ) is present along dendrites of cultured neurons, and exposure to estradiol results in an increase in ER cluster density. We hypothesized that estradiol may act through an ER-dependent mechanism and report that an ER antagonist blocks the estradiol-induced increase in synapse density, whereas an ER- $\alpha$ agonist mimics the effects of estradiol. These studies also reveal subcellular colocalization of NR1 and ER along dendrites, providing additional evidence that local signaling may occur between NMDARs and ERs to drive synaptogenesis. The essential link between ERs and estradiol, as well as between NMDAR function and estradiol, suggests that the NMDAR1-ER- $\alpha$ anatomical complex may contribute to the plasticity of early postnatal development in the hippocampus.

\section{Materials and Methods}

Primary hippocampal neuron cultures. Neuron and astrocyte cocultures were prepared from the hippocampus of female rat pups using previously established methods (Bekkers and Stevens, 1989). Briefly, brains from newborn rat pups [postnatal day 0 (P0)] were removed and placed in HBSS at $4^{\circ} \mathrm{C}$. Pooled hippocampi were digested in $5 \mathrm{ml}$ of $0.5 \%$ papain in Earle's balanced salt solution, $\mathrm{pH}$ 7.4, and dissociated by trituration through a fire-polished Pasteur pipette. The dissociated cell suspension was washed with neuronal (NEU) medium containing MEM, HEPES, GlutaMAX, dextrose, penicillin and streptomycin, charcoal-dextranstripped horse serum (10\%), and an N2 supplement composed only of insulin, human transferrin, putrescine, and selenite with no progesterone. The cells were pelleted by centrifugation at $1000 \mathrm{rpm}$ for $7 \mathrm{~min}$, resuspended in NEU medium, and plated. For the neuron/astrocyte cocultures, neurons were plated at a density of $30,000 \mathrm{cells} / \mathrm{ml}$ in 24 -well plates containing poly-D-lysine-coated coverslips previously subcultured
1 week before with astrocytes. For the neuron/astrocyte sandwich cultures, neurons were plated at a density of 30,000 cells $/ \mathrm{ml}$ on poly-Llysine-coated coverslips for $3 \mathrm{~h}$. The coverslips were then removed and placed into 12-well plates containing 1-week-old astrocyte bedlayers with supports for the neuron-seeded coverslip such that the neurons were suspended above the astrocyte feeder layer. Hippocampal astrocytes were isolated and grown up in astrocyte medium containing $20 \%$ charcoaldextran-stripped fetal bovine serum for 2 weeks before subculturing onto poly-D-lysine-coated coverslips or directly into 12-well plates.

Treatment with estradiol, ICI 182,780, or selective ER- $\alpha$ or ER- $\beta$ agonists. Hippocampal cultures were exposed to vehicle, $17 \beta$-estradiol (10 nм), $7 \alpha, 17 \beta-[9[(4,4,5,5,5$-pentafluoropentyl)sulfinyl $]$ nonyl $]$ estra1,3,5(10)-triene-3,17-diol (ICI 182,780) (1 $\mu \mathrm{M}), 1,3,5$-tris(4-hydroxyphenyl)-4-propyl-1 $H$-pyrazole (PPT; 1 and $10 \mathrm{~nm}$ ), 2,3-bis(4hydroxyphenyl) propionitrile (DPN; 1 and $10 \mathrm{~nm}$ ), or PPT and DPN (1 nM each) at specific times throughout the experiment $[0$ and $4 \mathrm{~d}$ in vitro (d.i.v.)]. In brief, a concentrated stock solution in ethanol of estradiol, ICI 182,780 , PPT, or DPN was diluted into NEU medium and added to cultures at 0 or 4 d.i.v. to produce a final $10 \mathrm{~nm}$ estradiol concentration and/or $1 \mu \mathrm{M}$ ICI 182,780 in the culture medium. The final agonist concentration was 1 or $10 \mathrm{~nm}$ for PPT and 1 or $10 \mathrm{~nm}$ for DPN. Cultures were fixed with $4 \%$ paraformaldehyde or $100 \%$ methanol at 6 d.i.v. for ICC.

Fluorescent ICC. ICC was performed on control and estradiol-treated cultures at 6 d.i.v. To identify clustering of NR1, vGlut1, and/or ER- $\alpha$ and ER- $\beta$ proteins, neuronal cultures were rinsed twice in cold PBS and fixed in $100 \%$ methanol for $5 \mathrm{~min}$ at $-20^{\circ} \mathrm{C}$. The cultures were immediately rinsed with PBS for 5 min and permeabilized in PBS containing $0.25 \%$ Triton X-100 for $5 \mathrm{~min}$. After a $30 \mathrm{~min}$ incubation with 10\% BSA, cultures were incubated at $4^{\circ} \mathrm{C}$ with mouse anti-NR1 (1:250; BD PharMingen, San Diego, CA), guinea pig anti-vGlut1 (1:2500; Chemicon, Temecula, CA), and/or rabbit ER- $\alpha$ antibody [1:15,000, C1355 (Upstate, Charlottesville, VA) or 1:2000, MC20 (Santa Cruz Biotechnology, Santa Cruz, CA)], and rabbit ER- $\beta$ antibody (1:2000, Z8P, lot 20470590; Zymed, South San Francisco, CA). The mouse monoclonal antibody to NR1 has been characterized by Western blots, ICC, and immunoaffinity purification (Brose et al., 1994) and by Western blots, ICC, and preadsorption (Siegel et al., 1994). The guinea pig polyclonal antibody against vGlut1 has been characterized by immunohistochemistry, electron microscopy, and preadsorption (Ni et al., 1994; Fremeau et al., 2001) and by Western blots and preadsorption (Bellocchio et al., 1998). The rabbit polyclonal ER- $\alpha$ antibody (C1355) has been characterized by Western blots and ICC (Solum and Handa, 2001), and the rabbit polyclonal ER- $\alpha$ antibody (MC20) has been characterized by blocking peptides (Kalita et al., 2005). The rabbit polyclonal ER- $\beta$ antibody (Zymed) specificity has been confirmed with preadsorption and double-label ICC/in situ hybridization studies (Shughrue et al., 1997). This specific lot has been tested and used by our lab for research studies (Suzuki et al., 2007). To identify ER proteins and microtubule-associated proteins [microtubuleassociated protein 2 (MAP2)] in dendrites, neuron/astrocyte cocultures were fixed in $4 \%$ paraformaldehyde for $15 \mathrm{~min}$ at $4^{\circ} \mathrm{C}$, permeabilized, blocked, and incubated with mouse anti-MAP2 (1:2000; Sigma, St. Louis, MO) and rabbit anti-ER- $\alpha$ (1:15,000, C1355; and 1:2000, MC20) or rabbit anti-ER- $\beta$ (1:2000). Controls were run in parallel within each ICC procedure and included a subset of fixed cultures incubated in blocking solution without primary antibodies to confirm the absence of nonspecific staining.

After overnight incubation with the antibodies, cultures were rinsed in $\mathrm{PBS}$ and $3 \% \mathrm{BSA}$ and then incubated with filtered $(0.22 \mu \mathrm{m}, 13 \mathrm{~mm}$ filter unit) fluorescent secondary antibodies Alexa 488 and 647 conjugates (Invitrogen, Eugene, OR) or $\mathrm{Cy} 2, \mathrm{Cy} 3$, and $\mathrm{Cy} 5$ conjugates (Jackson ImmunoResearch, West Grove, PA) at 1:400 in 3\% BSA for 45 min. Cultures were rinsed three times with PBS, dip rinsed in distilled water, and mounted with Fluormount 1,4-diazabicyclo[2.2.2] octane (Sigma).

Confocal imaging. Multichannel imaging of neurons and distal dendrites was performed with a Zeiss (Oberkochen, Germany) LSM 510 confocal microscope using a $63 \times$ water objective. Control and treated groups were coded and blindly run in parallel within the same immunocytochemical procedure. Three to seven immunostained neurons exhibiting pyramidal morphology were selected per coverslip, and secondary 
dendrites were routinely used for image capture and analysis. Because we report synapse density as synapse number per $20 \mu \mathrm{m}$ of dendrite on cultured hippocampal neurons, routinely selecting secondary dendrites allow for consistency in terms of relative thickness of the dendrites analyzed. In addition, by using only secondary dendrites, the confocal plane for image capture is maintained. Laser and detector settings were kept the same for all images collected within an immunocytochemical run. Channels were collected separately for each antibody with lasers set at 488, 564, and $647 \mathrm{~nm}$.

Protein distribution. In MetaMorph 6.1 imaging software (Molecular Devices, Downingtown, PA), the intensity of fluorescent images was thresholded by subtracting the mean and 1 SD of the diffuse cytoplasmic background. The images were binarized, and NR1, vGlut1, ER- $\alpha$, and ER- $\beta$ cluster density and size were determined on isolated dendrites. Regions of interest along a dendrite were 100-300 $\mu \mathrm{m}$ in length, and cluster density was normalized per $20 \mu \mathrm{m}$ of dendrite. Eight to 15 neurons for each treatment group from three separate cultures were analyzed. A cluster was defined as an aggregation of at least 2 pixels, corresponding to $0.19 \mu \mathrm{m}$.

Colocalization analysis. Using MetaMorph 6.1 imaging software, images of double-stained neurons were obtained separately for each channel and analyzed. Single-channel images were thresholded by subtracting the mean and $1 \mathrm{SD}$ of diffuse cytoplasmic background staining, and a binary image was created from each thresholded single-channel image. Binary images were then added together to display overlap, and a third binarized image of strict pixel overlap (colocalization) was used for colocalization analysis. Here, we define a synapse strictly as colocalized presynaptic protein (vGlut1) and postsynaptic protein (NR1) along dendrites. vGlut1 is the primary vesicular glutamate transporter found on hippocampal neurons, and NR1 is an obligate subunit of the NMDAR. Integrated morphometry analysis was performed to quantify protein cluster density and size in the colocalized binarized images. Regions of interest were determined on isolated dendrites anywhere from 100-300 $\mu \mathrm{m}$ in length, and cluster density was normalized per $20 \mu \mathrm{m}$ of dendrite. Percentage colocalization was calculated as colocalized clusters divided by the total number of NR1 or vGlut1 clusters. Integrated morphometry analysis was performed on 8-15 neurons for each treatment group from at least three separate cultures.

Statistical analysis. Data were analyzed by using two-way ANOVA, followed by Newman-Keuls post hoc comparison tests with Statistica 5.0 software (StatSoft, Tulsa, OK) or unpaired Student's $t$ tests with SigmaPlot 9.0 software (Systat Software, Richmond, CA). All data are expressed as mean \pm SEM. Differences were considered significant at $p<$ 0.05 .

\section{Results}

Estradiol increases NMDAR cluster size but not the density of clusters along dendrites

To examine the impact of estradiol on NR1 subunit protein distribution along dendrites of pyramidal neurons, primary rat hippocampal neurons were cultured on a bedlayer of astrocytes and exposed to estradiol ( $10 \mathrm{~nm}$ ) either from 4 to 6 d.i.v. or for the entire $6 \mathrm{~d}$ in culture. Cultures were fixed, and fluorescent ICC was performed at 6 d.i.v. Neurons selected for image analysis stained for glutamatergic presynaptic and postsynaptic proteins vGlut1 and NR1 and exhibited typical pyramidal cell morphology. Secondary dendrites were chosen that were not obscured by the astrocyte bedlayer or other neuronal processes. A total of $75.3 \pm$ $4.4 \%$ of the neurons in our cultures present as glutamatergic as analyzed by vGlut1 expression. After exposure to estradiol, this percentage did not change significantly $(76.2 \pm 2.7 \%)$.

Clusters containing NR1 immunoreactivity were observed along the dendrites as shown in Figure 1. NR1 cluster analysis was restricted to regions of interest along isolated secondary dendrites. NR1 cluster size increased significantly above control after exposure to estradiol for $48 \mathrm{~h}(10 \mathrm{~nm})$ or for prolonged $6 \mathrm{~d}$ (10 $\mathrm{nm}$ ) (Fig. $1 D)$. The average cluster size in untreated neurons
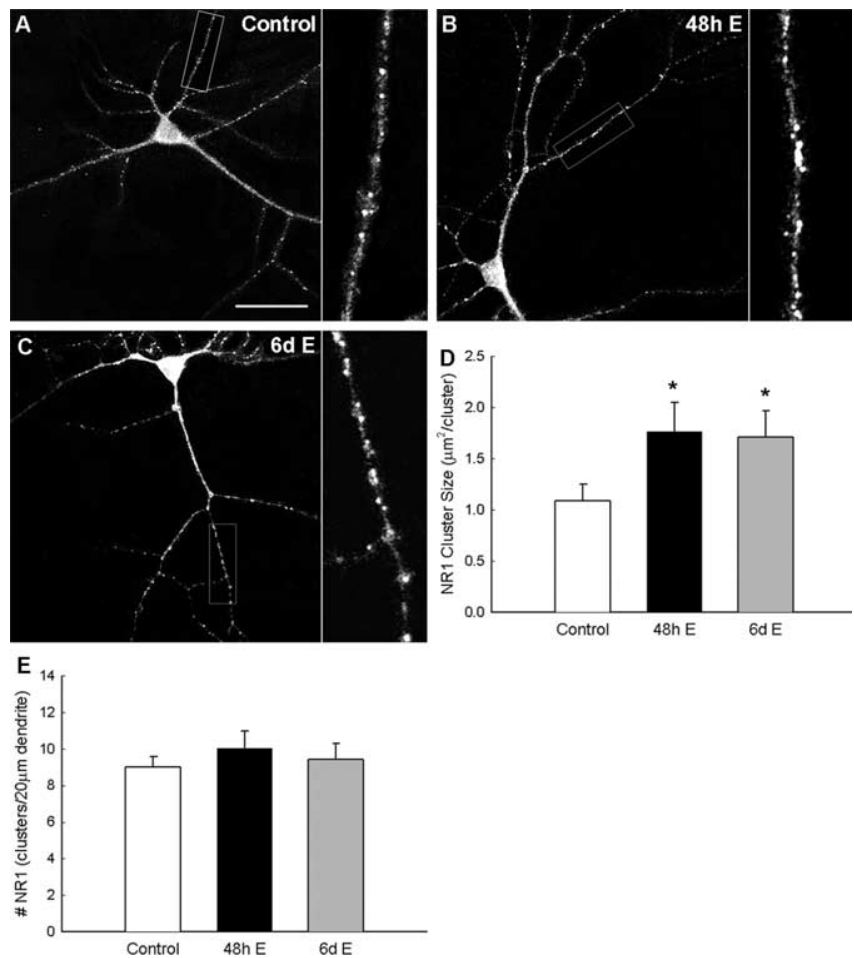

Figure 1. Estradiol (E; $10 \mathrm{~nm}$ ) exposure enhances the cluster size of NMDARs. ICC of NR1 and confocal imaging were used to examine the effect of estradiol exposure on NMDAR clustering and cluster size in hippocampal cultures. $\boldsymbol{A}-\boldsymbol{C}$, Confocal imaging of NR1 revealed punctate clustering of NMDARs in control cultures $(\boldsymbol{A})$. A $48 \mathrm{~h}$ exposure to estradiol $(10 \mathrm{~nm} ; \boldsymbol{B})$ and prolonged $6 \mathrm{~d}$ of exposure to estradiol ( $10 \mathrm{~nm} ; \boldsymbol{C}$ ) resulted in an increase in NR1 cluster size. $\boldsymbol{D}, \boldsymbol{E}$, Quantification of the effects of estradiol on clustering revealed a significant increase in NR1 cluster size $(\boldsymbol{D})$ and not in density $(\boldsymbol{E})$. All values are mean \pm SEM. The asterisk indicates a significant difference from control ( $p<0.05$, Student's $t$ test; $n=23-26$ ). Scale bar, $40 \mu \mathrm{m}$.

averaged $1.09 \pm 0.16 \mu \mathrm{m}^{2}$ per cluster ( $n=26$ neurons), whereas cluster size significantly increased to $1.76 \pm 0.29 \mu \mathrm{m}^{2}$ per cluster with $48 \mathrm{~h}$ estradiol exposure ( $p<0.04 ; n=24$ neurons) and to $1.71 \pm 0.26 \mu \mathrm{m}^{2}$ per cluster with estradiol exposure for the full $6 \mathrm{~d}$ of culture ( $p<0.04 ; n=23$ neurons). The effects of estradiol on NMDAR protein clustering did not significantly alter the density of NR1 clusters along dendrites of cultured neurons at 6 d.i.v. (Fig. $1 E$ ) [control, $9.00 \pm 0.59$ clusters per $20 \mu \mathrm{m}$ dendrite $(n=$ 26 neurons) vs $48 \mathrm{~h}$ estradiol exposure, $10.02 \pm 0.94(n=24$ neurons $)$ vs $6 \mathrm{~d}$ estradiol exposure, $9.41 \pm 0.89(n=23$ neurons)].

Estradiol alters NR1 localization profiles in dendrites of cultured hippocampal neurons, increasing cluster size to a similar degree in both exposure paradigms, the last $48 \mathrm{~h}$ of culture or prolonged $6 \mathrm{~d}$ exposure. A threshold response to estradiol based on concentration rather than length of exposure time may be occurring; alternatively, the response to estradiol may only occur at 4 d.i.v. and thereafter when ER expression is reportedly beginning in the hippocampus (Solum and Handa, 2001).

\section{Estradiol increases vGlut1 protein cluster size and density along dendrites}

Glutamatergic synapse formation requires the coordination of presynaptic nerve terminals and postsynaptic neurons, therefore the next series of experiments examined the effects of estradiol on the presynaptic glutamatergic protein vGlut1 cluster density and size. This protein is one of a family of proteins that is responsible for vesicular glutamate transport into synaptic vesicles. vGlut1 

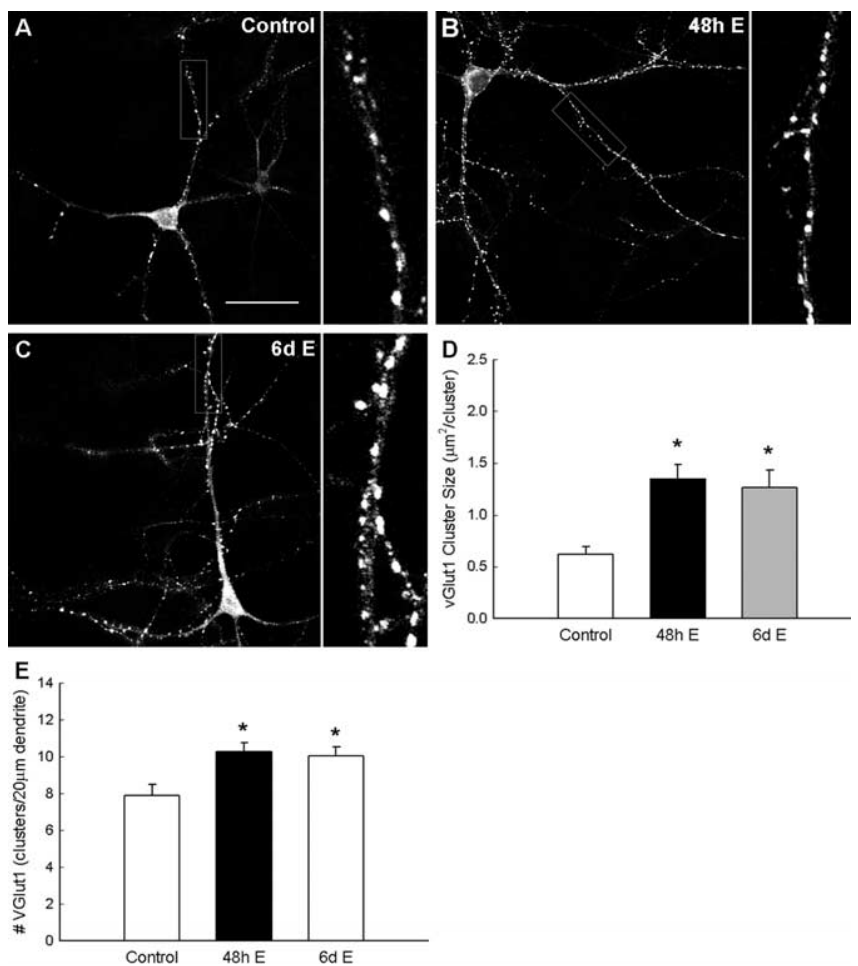

Figure 2. Estradiol (E; $10 \mathrm{~nm}$ ) exposure enhances the density and cluster size of vesicular glutamate transporter (vGlut1) proteins. ICC of vGlut1 and confocal imaging were used to examine the effect of estradiol exposure on vGlut1 clustering and cluster size in hippocampal cultures. $\boldsymbol{A}-\boldsymbol{C}$, Confocal imaging of vGlut1 revealed punctate clustering of vGlut1 in control cultures $(\boldsymbol{A})$. A $48 \mathrm{~h}$ exposure to estradiol $(10 \mathrm{~nm} ; \boldsymbol{B})$ and prolonged $6 \mathrm{~d}$ of exposure to estradiol $(10 \mathrm{~nm} ; \boldsymbol{C})$ resulted in an increase in cluster size and density. $\boldsymbol{D}, \boldsymbol{E}$, Quantification of the effects of estradiol on clustering revealed a significant increase in vGlut1 cluster size $(\boldsymbol{D})$ and vGlut1 cluster density $(\boldsymbol{E})$. All values are mean \pm SEM. The asterisk indicates a significant difference from control ( $p<0.05$ Student's $t$ test; $n=23-26$ ). Scale bar, $40 \mu \mathrm{m}$.

accounts for the ability of most established excitatory neurons to release glutamate by exocytosis (Bellocchio et al., 1998).

As shown in Figure 2, vGlut1 cluster size increased significantly in estradiol-treated neurons (Fig. 2D). The average cluster size in untreated neurons averaged $0.62 \pm 0.08 \mu \mathrm{m}^{2}$ per cluster ( $n=26$ neurons), with cluster size significantly increasing to $1.35 \pm 0.13 \mu \mathrm{m}^{2}$ per cluster ( $p<0.0008 ; n=24$ neurons $)$ after $48 \mathrm{~h}$ estradiol exposure and $1.26 \pm 0.17 \mu \mathrm{m}^{2}$ per cluster $(p<$ $0.007 ; n=23$ neurons) after estradiol exposure for the full $6 \mathrm{~d}$ of culture. In addition, acute $48 \mathrm{~h}$ or prolonged $6 \mathrm{~d}$ exposure to estradiol (10 nM) increased vGlut1 protein cluster density in axons that lie along dendrites of cultured hippocampal neurons (Fig. $2 E$ ). Cluster density significantly increased at 6 d.i.v. from $7.89 \pm 0.62$ clusters per $20 \mu \mathrm{m}$ dendrite ( $n=26$ neurons), length in vehicle-exposed cultures increased to $10.26 \pm 0.51(p<0.005$; $n=24$ neurons) and to $10.06 \pm 0.47$ ( $p<0.09 ; n=23$ neurons $)$ in $48 \mathrm{~h}$ or $6 \mathrm{~d}$ estradiol-exposed cultures, respectively.

Estradiol increases density and size of synaptic clusters along dendrites of cultured hippocampal neurons and enriches NMDAR protein at these sites

Synapses arise from the differential distribution and concentration of specific presynaptic and postsynaptic proteins, the precise co-organization of which gives rise to proper function. To examine the effect of estradiol on synaptic protein localization, we visualized glutamatergic synaptic sites or clusters using antibod- ies to vGlut1, as a presynaptic marker, and the obligatory NR1 subunit of the NMDAR, as a postsynaptic marker. We compared the number and location of synapses, colocalized NR1 and vGlut1 proteins, in sets of randomly selected control and estradiol-treated pyramidal hippocampal neurons (Fig. 3A-F). We have determined synapse density through protein colocalization and therefore cannot report on the functional characteristics of the synapses.

Application of estradiol at a dose of $10 \mathrm{~nm}$, substantially less than used in previous in vitro studies to induce spinogenesis (Murphy and Segal, 1996), led to a reliable, statistically significant increase in synapse density along dendrites. Synapses increased by $48 \%$, with initial counts of $4.59 \pm 0.47$ clusters per $20 \mu \mathrm{m}$ dendrite ( $n=26$ neurons) in vehicle-exposed cultures to $6.79+$ $0.35(p<0.0005 ; n=24$ neurons $)$ and $6.52 \pm 0.41(p<0.003$; $n=23$ neurons) in cultures treated with estradiol for $48 \mathrm{~h}$ or $6 \mathrm{~d}$, respectively (Fig. $3 G$ ). The average cluster size of the synapses significantly changed as well, increasing from $0.40 \pm 0.05 \mu \mathrm{m}^{2}$ per cluster ( $n=26$ neurons) to $0.82 \pm 0.12 \mu \mathrm{m}^{2}$ per cluster $(p<$ $0.0016 ; n=24$ neurons $)$ and $0.83 \pm 0.10 \mu \mathrm{m}^{2}$ per cluster $(p<$ $0.0003 ; n=23$ neurons), respectively (Fig. $3 H$ ).

To examine the subcellular localization of dendritic NR1 clustering, we examined the percentage of NR1 clusters at synaptic sites (Fig. 3J) with and without exposure to estradiol. In control cultures, $57.64 \pm 6.15 \%$ ( $n=1175$ clusters, 26 neurons $)$ of NR1 protein clusters were found at synaptic clusters (those areas where both NR1 and vGlut1 colocalized), with the remaining NMDAR protein clusters being extrasynaptic. Exposure to estradiol for $48 \mathrm{~h}$ ( $10 \mathrm{nM}$ ) or chronic 6 d exposure (10 nM) significantly increased synaptic localization of NR1 clusters to $84.44 \pm 5.15 \%$ ( $p<0.002 ; n=1240$ clusters, 24 neurons) and $79.10 \pm 5.5 \%$ ( $p<0.01 ; n=1082$ clusters, 23 neurons), respectively. Because no increase in NR1 cluster number was observed (Fig. $1 E$ ), estradiol targets the NMDAR to synaptic sites. The observed change in NR1 localization could involve relocation of previously existing NR1 receptors from nonsynaptic to synaptic sites, or a shift in targeting of newly synthesized receptor. The estradiol-induced increase of NR1 clusters to synaptic sites suggests that NMDAR transport along the dendrite may be altered or, alternatively, receptor protein stabilization may be occurring.

Estradiol preferentially induces synaptic targeting of NMDARs, enriching NR1 protein at synaptic clusters after estradiol exposure. In contrast, estradiol does not enrich the presynaptic vGlut1 protein at synaptic clusters (Fig. $3 \mathrm{~K}$ ). Approximately $59.17 \pm 3.65 \%$ ( $n=1025$ clusters, 26 neurons $)$ of vGlut 1 proteins were localized at synaptic clusters, and this percentage did not significantly differ with estradiol exposure [48 h exposure, $68.92 \pm 3.21 \%(n=1231$ clusters, 24 neurons $)$; chronic $6 \mathrm{~d}$ exposure, $69.6 \pm 4.27 \%$ ( $n=1157$ clusters, 23 neurons $)]$.

It is well established that NMDAR activity blockade inhibits the estradiol-induced increase in spine density and synaptogenesis; thus, we determined whether estradiol was preferentially affecting synaptic or extrasynaptic NR1 protein clusters. Because estradiol induced an increase in NR1 cluster size, we compared changes in cluster size of NR1 clusters localized at synaptic clusters to changes in cluster size at extrasynaptic sites. Estradiolinduced increases in NR1 cluster size occurred exclusively at synaptic sites (from $0.63 \pm 0.05 \mu \mathrm{m}^{2}$ per cluster to $0.97 \pm 0.08$ per cluster; $p<0.0005 ; n=39$ neurons) and was accompanied by no change in the cluster size of NR1 clusters at nonsynaptic sites (Fig. $3 L$ ). 

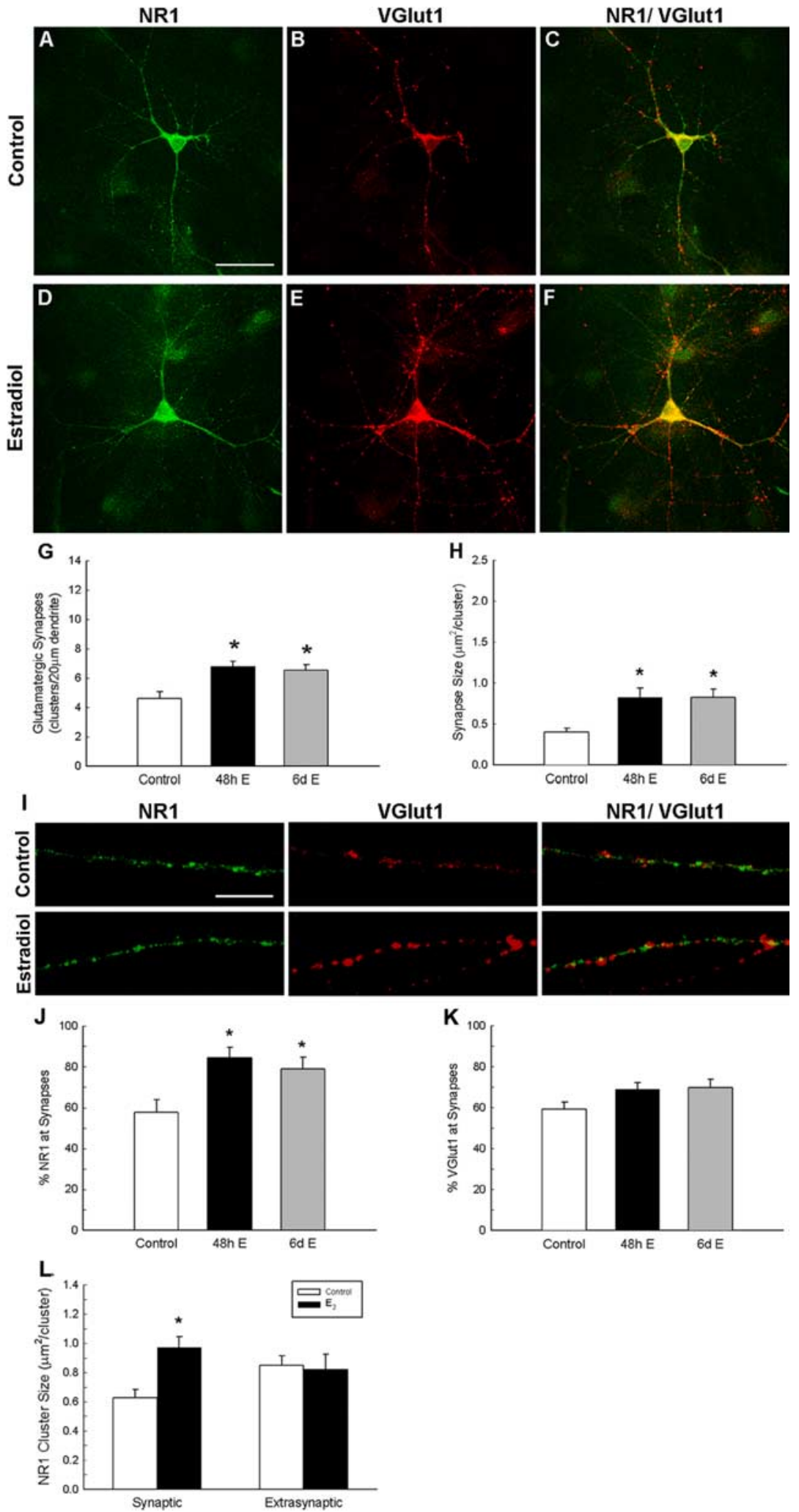

Figure 3. Estradiol treatment increases synaptic cluster density and cluster size. $\boldsymbol{A}-\boldsymbol{F}, \boldsymbol{I}$, Double-label ICC for NR1 (green) and vGlut1 (red); yellow in the superimposed images indicates colocalization. $\boldsymbol{G}, \boldsymbol{H}$, Estradiol treatment significantly increased the density of colocalized NR1 and vGlut1 clusters $(\boldsymbol{G})$ and cluster size $(\boldsymbol{H})$. ${ }^{*}$ Significant difference from control (48 h: $p<0.0005, n=$ 24; $6 \mathrm{~d}: p<0.003, n=23$; Student's $t$ test). J, Quantification of NR1 at synaptic clusters revealed that estradiol also significantly increases the percentage of NR1 proteins. The asterisk indicates a significant difference from control $[48 \mathrm{~h}, p<0.002(n=24)$ and $p<0.01$ ( $n=23)$; Student's $t$ test]. $\boldsymbol{K}$, Quantification of vGlut1 at synaptic clusters showed no difference between control and treated hippocampal pyramidal neurons. $L$, The estradiol-induced increase in NR1 cluster size was limited to the synaptic compartment ( $p<0.0005$, Student's $t$ test; $n=39$ ) with no changes occurring in extrasynaptic NR1 clusters $(p<0.81$, Student's test; $n=39)$. All values are mean \pm SEM. Scale bars: $\boldsymbol{A}-\boldsymbol{F}, 40 \mu \mathrm{m} ; \boldsymbol{I}, 10 \mu \mathrm{m}$.
ER proteins are expressed in cultured hippocampal neurons, and estradiol increases extranuclear density of ER- $\alpha$ and ER- $\boldsymbol{\beta}$ along dendrites

In initial studies, we sought to determine whether ERs were present in cells that stained positively for the neuronal protein dendritic marker MAP2. ER- $\alpha$ and ER- $\beta$ intense immunoreactivity was observed in nuclei of dissociated hippocampal pyramidal neurons that colabel with MAP2 as shown in Figure 4. Representative micrographs of ER- $\alpha$ - and ER- $\beta$-immunoreactive nuclei are shown in red (Fig. $4 A, D)$, MAP2 immunoreactivity within the cytoplasm is shown in blue (Fig. $4 B, E)$, and the overlay is shown in Figure 4, $C$ and $F$. The majority of MAP2-positive cells at 6 d.i.v. were immmunoreactive for ER; however, nuclear staining intensity qualitatively varied among the cells. In our hippocampal cultures, no ER- $\alpha$ immunoreactivity was detectable at 1 d.i.v. (data not shown). Together, these data are consistent with in vivo reports that suggest little or no ER- $\alpha$-positive cells in the hippocampal formation of rat pups on $\mathrm{P} 0$; however, transient increases in ER- $\alpha$ immunoreactivity from $\mathrm{P} 2-\mathrm{P} 3$ to $\mathrm{P} 10$ (O'Keefe and Handa, 1990; Solum and Handa, 2001).

In addition to nuclear ER immunostaining, low-intensity fluorescent immunostaining could be detected by highresolution confocal microscopy along the dendrites of cultured hippocampal neurons immunostained for ER. Because ER- $\alpha$ - and ER- $\beta$-immunoreactive clusters along dendrites of cultured neurons were confounded by immunopositive staining in the astrocyte bedlayer, we cultured neurons on poly-L-lysine-coated coverslips and suspended them above a bedlayer of astrocytes (sandwich culture) to gain the resolution to quantify ER- $\alpha$ and ER- $\beta$ cluster density and size along dendrites as shown in Figure 5. We initially confirmed that the hippocampal neurons incubated within the sandwich culture paradigm respond to $48 \mathrm{~h} 10 \mathrm{~nm}$ estradiol treatment with a significant increase in synapse cluster density and size (data not shown) and then performed studies to quantify ER- $\alpha$ and ER- $\beta$ cluster density in cultures exposed to vehicle or $48 \mathrm{~h}$ estradiol treatment.

To determine whether estradiol treatment alters the density or size of dendritic ER- $\alpha$ clusters, we used ICC with two previously characterized polyclonal antibodies to ER- $\alpha$. Rabbit polyclonal C1355 anti-ER- $\alpha$ and rabbit polyclonal MC20 anti-ER- $\alpha$ showed the same pattern of staining in den- 
drites of control and estradiol-treated neurons. ER- $\alpha$ cluster density along dendrites of cultured hippocampal neurons was determined for each antibody. C1355 detected more clusters along dendrites in control cultures $(9.7 \pm 0.77$ clusters per 20 $\mu \mathrm{m}$ dendrite; $n=10$ neurons) in our initial experiments than MC20 (6.12 \pm 1.01 clusters per $20 \mu \mathrm{m}$ dendrite; $n=10$ neurons). However, both antibodies detected a significant increase in ER- $\alpha$ cluster density after a $48 \mathrm{~h} 10 \mathrm{~nm}$ estradiol treatment. On average, a $31.6 \%$ ( $n=1260$ clusters; $p<0.05)$ increase in clusters was detected along dendrites of cultured hippocampal neurons suspended above an astrocyte bedlayer using the C1355 anti-ER- $\alpha$ antibody, whereas MC20 anti-ER- $\alpha$ detected a $28.4 \%$ increase $(n=800$ clusters; $p<$ 0.05) (data not shown). C1355 was selected for subsequent experiments because of increased sensitivity.

Because there is considerable speculation of local signaling between ERs and proteins in neuronal processes, we quantitated and compared the distribution of NR1 and ER- $\alpha$ protein clusters (Fig. 5A) and the distribution of NR1 and ER- $\beta$ protein clusters (Fig. 5B) along dendrites of control and estradiol-treated neurons. Neurons on glass coverslips suspended above an astrocyte bedlayer were treated for $48 \mathrm{~h}$ with10 $\mathrm{nm}$ estradiol, fixed with methanol at 6 d.i.v., and subjected to immunocytochemical staining with antibodies against ER- $\alpha$ and NR1 or ER- $\beta$ and NR1.

Quantification of ER- $\alpha$ revealed that ER- $\alpha$ cluster density increased to $12.83 \pm$ 0.50 clusters per $20 \mu \mathrm{m}$ dendrite $(p<$ $0.03 ; n=33$ ) after estradiol exposure compared with age-matched control wells $(9.81 \pm 0.53$ clusters per $20 \mu \mathrm{m}$ dendrite) (Fig. $5 C$ ). Because neurons were on glass, background levels of staining were absent or very low, facilitating the identification of labeled cells. No staining was observed with omission of the primary antibody. To investigate the possibility that estradiol may increase synaptogenesis in our cultures because of enhanced NR1 and ER subcellular anatomical association, we an-

alyzed the number of ER- $\alpha$ clusters that colocalized with NR1 before and after estradiol treatment. Estradiol treatment did not change the density of colocalized NR1/ER- $\alpha$ protein clusters (Fig. $5 C)$. A total of $57.5 \%$ of the ER- $\alpha$ colocalized with NR1 in dendrites of control neurons, and this percentage did not change significantly (45.7\%) after estradiol treatment, suggesting estradiol is not driving increased subcellular association of the two proteins.

ER- $\beta$ protein is present in the dendrites of our cultured hippocampal neurons. ER- $\beta$ protein cluster density increases after $48 \mathrm{~h}$ estradiol exposure ( $10 \mathrm{~nm}$ ) by $51 \%$ along dendrites of cul-
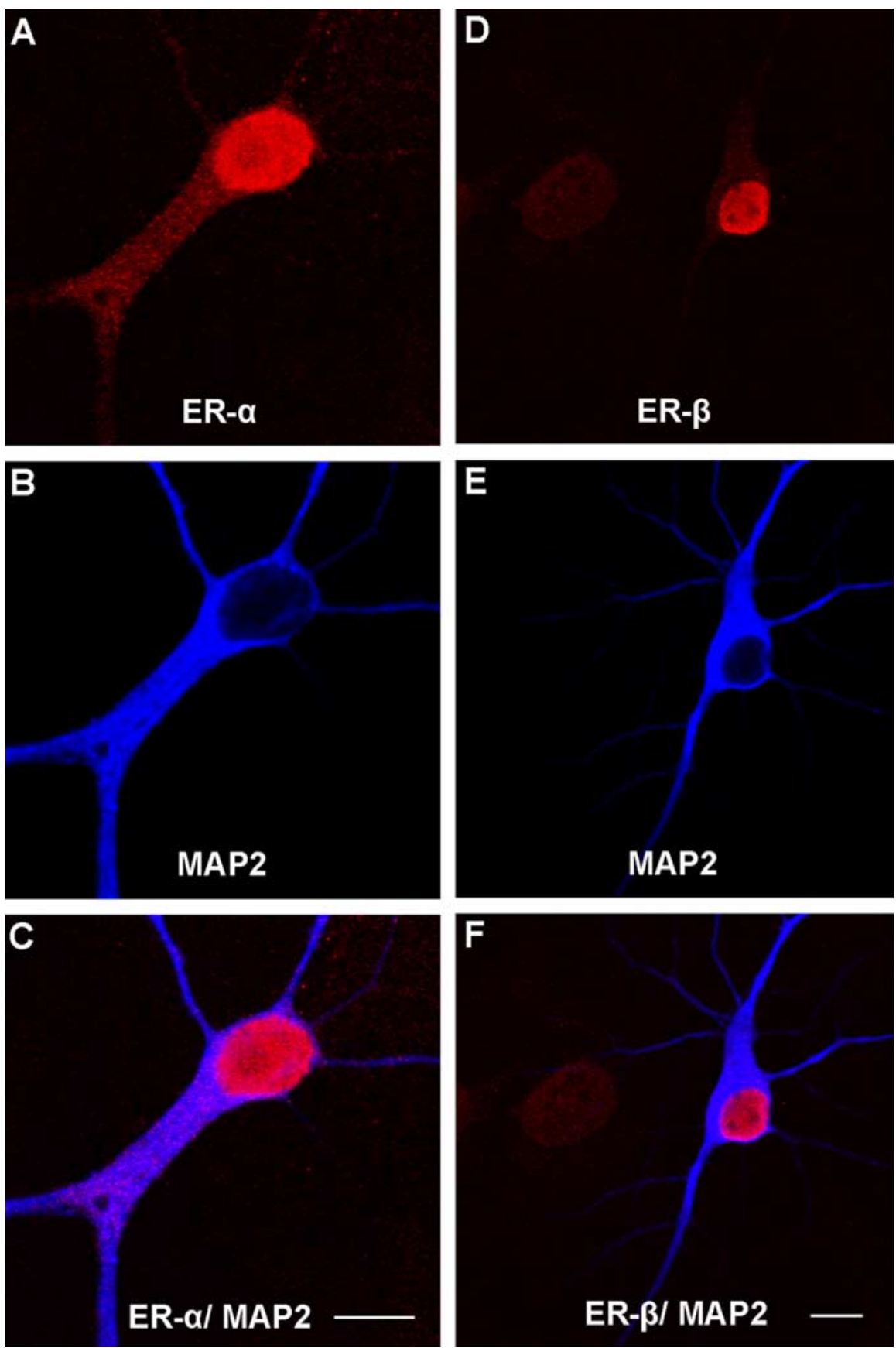

Figure 4. $\quad \boldsymbol{A}, \boldsymbol{B}, \boldsymbol{D}, \boldsymbol{E}$, Double-label fluorescent ICC for $E R-\alpha$ and MAP2 $(\boldsymbol{A}, \boldsymbol{B})$ or $E R-\beta$ and MAP2 $(\boldsymbol{D}, \boldsymbol{E})$ in cultured hippocampal neurons grown on a bedlayer of astrocytes at 6 d.i.v. $C, F$, Low-magnification representative micrographs of ER- $\alpha / M A P 2$ and ER- $\beta$ /MAP2 overlay reveal immunoreactive nuclei and some diffuse ER- $\alpha$ and ER- $\beta$ cytoplasmic staining in MAP2-positive neurons. Subsequent fluorescent ICC and confocal imaging was used to identify ER- $\alpha$ and ER- $\beta$ clusters along dendrites of hippocampal neurons cultured on glass coverslips suspended above a bedlayer of astrocytes at 6 d.i.v. Scale bars, $10 \mu \mathrm{m}$.

tured neurons (from control well values of $8.46 \pm 1.09$ clusters per $20 \mu \mathrm{m}$ dendrite to $12.81 \pm 0.90$ clusters per $20 \mu \mathrm{m}$ dendrite in estradiol-treated wells; $p<0.003 ; n=35$ ) (Fig. $5 D$ ). As expected, NR1 cluster density along dendrites does not change regardless of estradiol exposure. Colocalized NR1/ER- $\beta$ clusters significantly increase after estradiol exposure $(p<0.003 ; n=$ 35). However, because there is both a significant increase in ER- $\beta$ clusters as well as colocalized NR1/ER- $\beta$ clusters, statistical analysis reveals no difference between the percentage of ER- $\beta$ proteins colocalized with NR1 in control wells (47.4\%) and estradiol-treated wells (53.6\%), suggesting estradiol is not driv- 


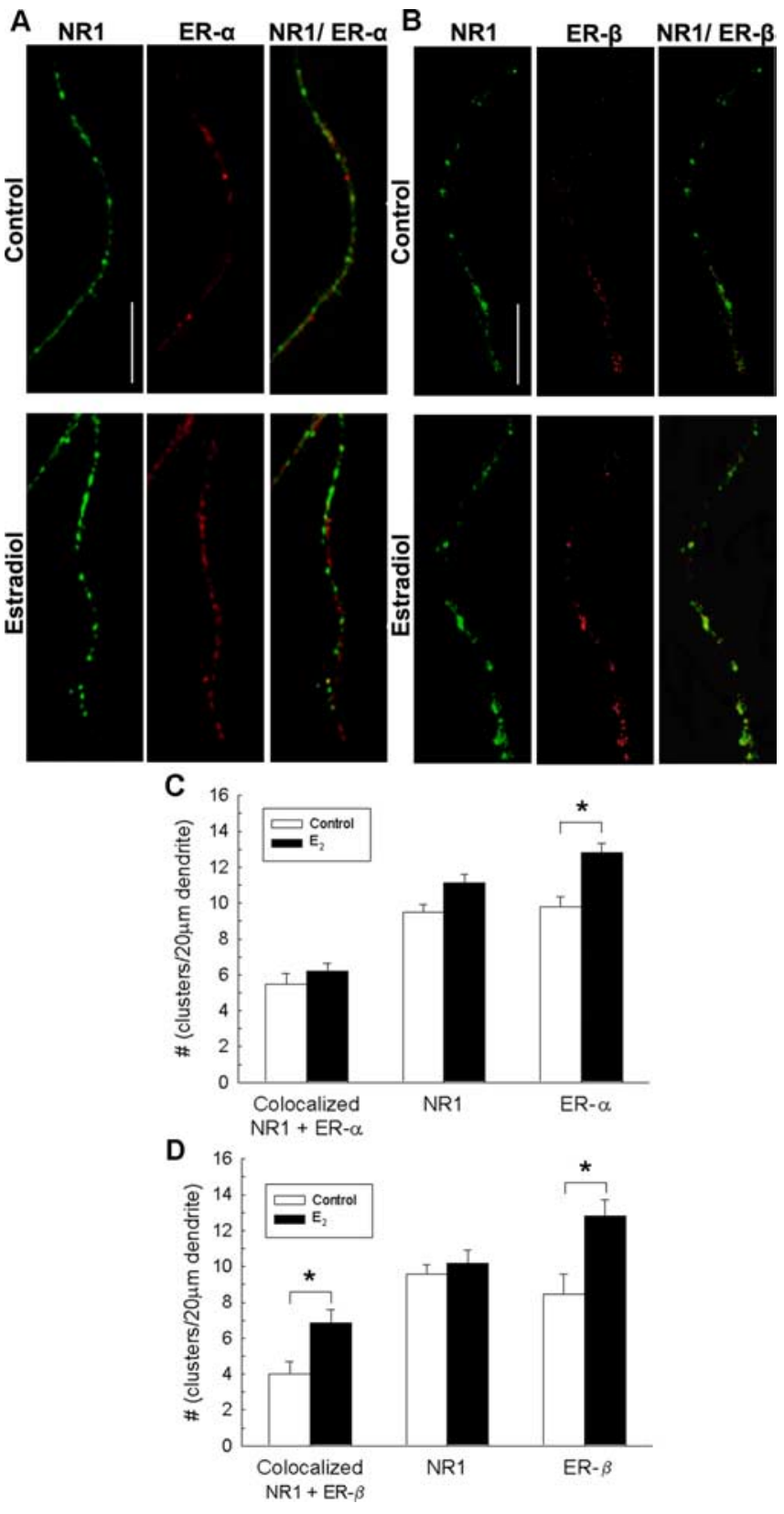

Figure 5. A, Double-label ICC for NR1 (green) and ER- $\alpha$ (red); yellow in the superimposed images indicates colocalization of representative micrographs from control and estradioltreated cultures of rat hippocampal neurons cultured alone on glass coverslips grown in culture wells suspended above astrocyte bedlayer. ER- $\alpha$ clusters displayed a fine punctuate pattern in control cultures as detected by the (1355 polyclonal antibody. B, Double-label ICC for NR1 (green) and ER- $\beta$ (red); yellow in the superimposed images indicates colocalization of representative micrographs from cultures of rat hippocampal neurons cultured alone on glass coverslips grown in culture wells suspended above astrocyte bedlayer. ER- $\beta$ clusters displayed a fine punctuate pattern in control cultures as detected by the Zymed polyclonal antibody. C, Quantification of the average cluster density of NR1, ER- $\alpha$, and colocalized NR1/ER- $\alpha$ observed in control and estradiol-treated cultures revealed that estradiol treatment significantly increases the density of ER- $\alpha$ clusters ( ${ }^{*} p<0.03$, Student's $t$ test; $n=33$ ). Comparison of control and estradiol-treated neurons revealed no significant difference in cluster density of NR1 proteins and colocalized NR1/ER- $\alpha$ proteins. D, Quantification of the average cluster density of NR1, ER- $\beta$, and colocalized NR1/ER- $\beta$ observed in control and estradiol-treated cultures revealed that estradiol treatment significantly increases the density of ER- $\beta$ clusters ( ${ }^{*} p<0.003$, Student's $t$ test; $n=35$ ) and colocalized NR1/ER- $\beta$ ( ${ }^{*} p<0.007$, Student's $t$ test; $n=35$ ). Comparison of control and estradiol-treated neurons revealed no significant difference in cluster density of NR1 proteins. All values are mean \pm SEM. The asterisks indicate a significant difference from control. Scale bar, $10 \mu \mathrm{m}$. $\mathrm{E}_{2}$, Estradiol. ing significant subcellular association of ER- $\beta$ and NR1 along the dendrite.

ICI 182,780 inhibits estradiol-induced synaptogenesis

If estradiol-induced synaptogenesis is mediated by the ER, increases in synapse density along dendrites should revert to control levels with ER blockade. To test this hypothesis, cultures were treated with the pure ER antagonist ICI 182,780 (1 $\mu \mathrm{M}) 1 \mathrm{~h}$ before estradiol (10 nM) exposure. Pretreatment with ICI 182,780 resulted in synapse number $\left(5.15 \pm 0.43 \mu \mathrm{m}^{2}\right.$ per cluster; $n=18$ neurons) similar to that observed in age-matched controls (4.33 $\pm 0.39 \mu \mathrm{m}^{2}$ per cluster; $n=20$ neurons) and significantly lower than that observed in estradiol-treated cultures $(7.64 \pm$ $0.43 \mu \mathrm{m}^{2}$ per cluster; $n=18$ neurons; control, $p<0.0002$; ICI/ estradiol, $p<0.0002$ ) (Fig. 6). Thus, estradiol-induced synaptogenesis in our young hippocampal neurons during in vitro development is ER mediated.

Because enzymes of steroidogenesis are expressed in hippocampal neurons (specifically aromatase the enzyme responsible for conversion of testosterone to estradiol), a percentage of synapses in our control cultures may be driven by reported endogenous estradiol production by astrocytes or neurons (PrangeKiel et al., 2003; Hojo et al., 2004). Thus, cultures were treated with the ER antagonist ICI 182,780 alone for the $48 \mathrm{~h}$ time period between 4 and 6 d.i.v. ICI 182,780 exposure alone resulted in synapse number $\left(5.06 \pm 0.48 \mu \mathrm{m}^{2}\right.$ per cluster; $n=19$ neurons) similar to that observed in age-matched controls $(4.33 \pm 0.39$ $\mu \mathrm{m}^{2}$ per cluster; $n=20$ neurons) and significantly lower than estradiol-treated cultures (Fig. 6), suggesting that endogenous estradiol interacting with the ER may not contribute to initial synapse formation in our cultures.

\section{The ER- $\alpha$ agonist PPT can increase synapse density along} dendrites that mimics treatment with estradiol

Estradiol is the endogenous ligand for both receptor subtypes cloned to date, ER- $\alpha$ and ER- $\beta$. ER- $\alpha$ and/or ER- $\beta$ are functionally important because the ER antagonist ICI 182,780 was capable of inhibiting estradiol-induced synaptogenesis. To test whether ER- $\alpha$ and/or ER- $\beta$ activation is capable of increasing synapse number, hippocampal cultures on astrocyte bedlayers were exposed $48 \mathrm{~h}$ (4-6 d.i.v.) to agonists. Cultures were exposed to the potent ER- $\alpha$-selective agonist PPT at concentrations of either 1 or $10 \mathrm{nM}$ or the potent ER- $\beta$-selective agonist DPN at 1 or $10 \mathrm{nM}$. As depicted in Figure 7, estradiol exposure (10 nM) significantly increased synapse clusters (colocalized NR1and vGlut) to $8.62 \pm$ 0.50 clusters per $20 \mu \mathrm{m}$ dendrite compared with vehicle-treated wells $(6.15 \pm 0.53$ clusters per $20 \mu \mathrm{m}$ dendrite; $p<0.027 ; n=$ 22). Only PPT, the potent ER- $\alpha$ agonist, at $10 \mathrm{nM}$ significantly increased the density of synaptic clusters to $8.41 \pm 0.51$ clusters per $20 \mu \mathrm{m}$ dendrite compared with vehicle-exposed control cultures $(p<0.0417 ; n=21)$, as analyzed by an ANOVA statistical test. With significance arbitrarily set at $p<0.05$, the potent ER- $\beta$ agonist DPN, at concentrations of 1 and $10 \mathrm{nM}$, increased synaptic cluster density to $7.80 \pm 0.54$ clusters per $20 \mu \mathrm{m}$ dendrite $(p<$ $0.10 ; n=24)$ and $8.09 \pm 0.59$ clusters per $20 \mu \mathrm{m}$ dendrite $(p<$ $0.07 ; n=20$ ), respectively, representing values that show a trend but fall short of statistical significance. Exposure to PPT (1 nM) and DPN (1 nM) in combination did not result in a significant increase in cluster density along dendrites (not shown on graph) (7.28 \pm 0.49 clusters per $20 \mu \mathrm{m}$ dendrite; $p<0.16 ; n=18$ ).

\section{Discussion}

The present study clearly shows that estradiol treatment (1) alters subcellular localization and size of presynaptic and postsynaptic 
protein clusters involved in glutamatergic synapse formation, (2) stimulates an increase in extranuclear ER- $\alpha$ and ER- $\beta$ protein cluster density, and (3) increases synapse density through an ER- $\alpha$ dependent mechanism in dendritic processes of hippocampal neurons undergoing in vitro development. Using presynaptic and postsynaptic markers of synaptogenesis and confocal microscopy, we demonstrate that exposure to estradiol affects the distribution of both presynaptic vesicular glutamate transporter proteins as well as NMDARs during glutamatergic synapse formation, ultimately giving rise to an increase in synapse density. The present study confirms that estradiol-induced synaptogenesis is mediated by the ER because the effects of estradiol on synapse number could be blocked by the pure ER antagonist ICI 182,780. With the use of agonists, we show that estradiolinduced synaptogenesis can be mediated by ER- $\alpha$, and not ER- $\beta$, although both ER subtypes are expressed at extranuclear sites along dendrites and colocalize with NMDARs. These observations carry profound implications for the significance of hormonal milieu and ER- $\alpha$ expression within the developing brain.

\section{NR1 and vGlut1 synaptic protein distribution significantly changes in response to estradiol exposure: implications for estradiol in NMDAR trafficking}

Previous studies have established that estradiol increases the number of synapses in more mature hippocampal neurons (Murphy and Segal, 1996; Pozzo-Miller et al., 1999). Our study extends these findings and quantifies the relative distribution and size of NR1 and vGlut1 protein clusters and their colocalization at synapses during the initial stages of synapse formation between hippocampal neurons derived from female rat pups. Because our cultures are derived from only females, ER expression and response to estradiol may differ from that in a mixed-sex culture scenario (Murphy and Segal, 1996). The homogeneity of ER expression in a female-only culture may facilitate the stimulatory and consistent response to estradiol. $17 \beta$ Estradiol enriches the NR1 subunit of the NMDAR at synaptic sites and selectively increases the synaptic NMDA cluster size without altering extrasynaptic cluster size, indicating an important role for estradiol in glutamatergic synaptogenesis. Such a pattern of expression suggests that the estradiol-induced acquisition of NR1 to sites of developing glutamatergic synapses may be regulated at the level of the individual synapse. Because the estradiol-induced increase in NR1 cluster size occurs exclusively at synaptic clusters, estradiol-induced neuroadaptive changes may occur through processes that regulate NMDA synaptic targeting and localization. This may explain the results of previous

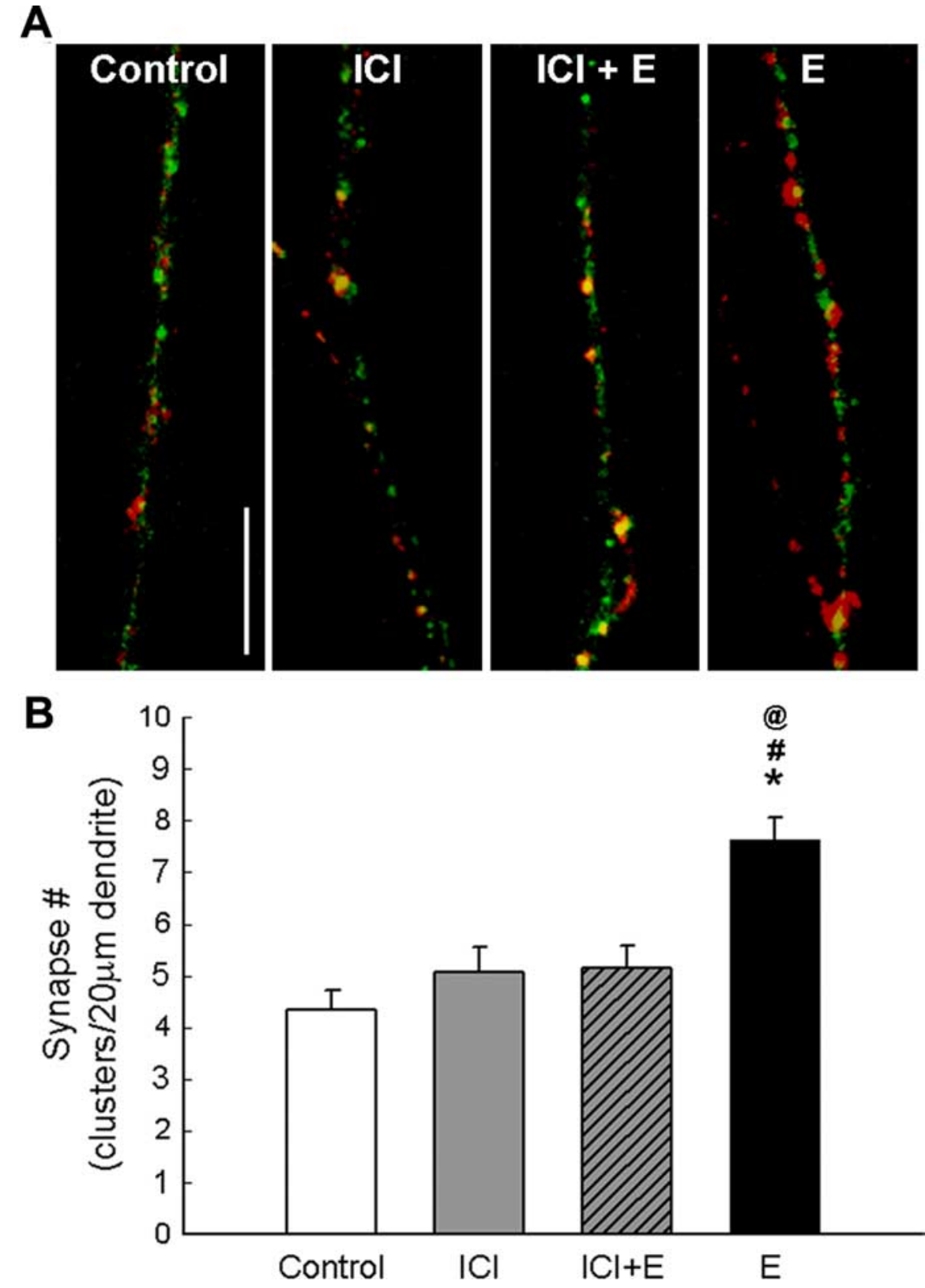

Figure 6. A, Estradiol-induced increase in synaptic cluster density is inhibited in neuron cultures pretreated with ICI 182,780 (1 $\mu \mathrm{m})$, an ER antagonist, before estradiol exposure. Scale bar, $10 \mu \mathrm{m}$. B, Quantification of NR1 (green) and vGlut1 (red) colocalizaestradiol, were also no different than control levels. ${ }^{*}$, Significant difference from control; \#, significant difference from estradio and ICI treated; @ , significant difference from ICI-only treated ( $p<0.01$, ANOVA with Newman-Keuls post hoc; $n=18-29)$. All values are mean \pm SEM. E, Estradiol; ICl, ICl 182,780.

studies that demonstrated that estradiol increases NMDAR agonist binding sites (Weiland, 1992) and binding in the hippocampus (Romeo et al., 2005), upregulates NMDAR1 subunit proteins within neurons (Gazzaley et al., 1996), and increases NMDAR transmission in the hippocampus (Woolley et al., 1997; Foy et al., 1999; McEwen et al., 2001; Smith and McMahon, 2005).

This ability of estradiol to differentially alter trafficking of NMDARs between spatially resolved and functionally distinct synaptic and extrasynaptic domains may be a mechanism to influence plasticity. Estradiol may induce targeting of synaptic proteins through (1) NMDAR trafficking, given the association of NMDAR1 protein with microtubules in dendrites, (2) changes in surface expression of NMDARs, and/or (3) stabilization of syn- 


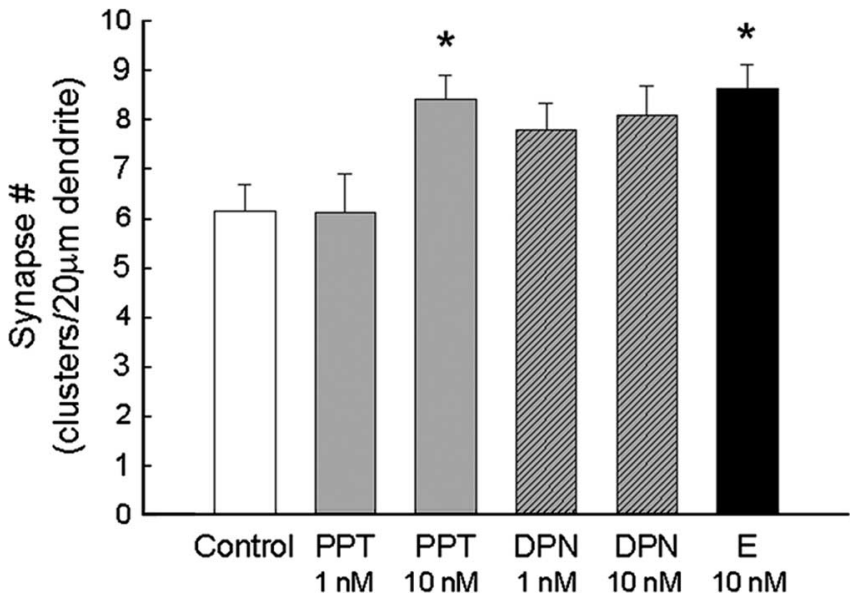

Figure 7. The ER- $\alpha$ agonist PPT (10 nm) increases the number of synapses similar to that observed with estradiol (E) in hippocampal neurons undergoing in vitro development. ICC and confocal imaging of colocalized NR1 and vGlut1 proteins were used to determine the effects of the ER- $\alpha$-specific agonist PPT and ER- $\beta$-specific agonist DPN on the density of synaptic clusters along dendrites. *Significant increase above control was found with exposure to estradiol (10 $\mathrm{nm} ; 48 \mathrm{~h} ; p<0.027$, ANOVA with Newman-Keuls post hoc; $n=22$ ) and the ER- $\alpha$-specific agonist PPT ( $10 \mathrm{~nm} ; 48 \mathrm{~h} ; p<0.034$, ANOVA with Newman-Keuls post hoc; $n=20)$. Comparison of vehicle-treated neurons to PPT-treated (1 nM), DPN-treated (1 nM), and DPN-treated (10 nм) neurons revealed no significant differences in synapse density when treatment groups were analyzed together by ANOVA with Newman-Keuls post hoc comparison. All values are mean \pm SEM.

aptic protein complexes. NMDARs interact with numerous proteins to affect the functional properties and organization of developing glutamatergic synapses. It is known that at least $65 \%$ of synaptic NMDAR are mobile and transported between synaptic and extrasynaptic pools (Tovar and Westbrook, 2002) along microtubule tracks in dendritic shafts before being delivered to synapses (Washbourne et al., 2002, 2004) and estradiol can modify the cytoskeleton (Shah et al., 2003; Reyna-Neyra et al., 2004) and drive PSD-95 (postsynaptic density-95) synthesis (Akama and McEwen, 2003).

Our data also demonstrate that estradiol can increase presynaptic vGlut1 protein cluster density and size along dendrites of hippocampal neurons during in vitro development. This enhanced presynaptic size would allow more glutamatergic vesicles at the site of NR1 clusters and may reflect the demand for more glutamatergic vesicles at the multisynapse bouton formations (Woolley et al., 1996). ERs appear positioned to provide local signals related to axon growth and early synapse formation by altering the transport of synaptic vesicle proteins (Sabo and McAllister, 2003).

Previous research in cultured hippocampal neurons provide evidence that estradiol works indirectly on spiny pyramidal neurons through aspiny inhibitory GAD-expressing interneurons ( $\sim 12-21 \%$ of neurons in the cultures), which were identified as ER expressing (Murphy et al., 1998). Since that time, however, ER expression has been found in glutamatergic neurons of the hippocampus. Our results corroborate these findings, thus implicating an active role for glutamatergic neurons as well as GABAergic neurons. We detect ERs in the nucleus and dendritic processes of cultured hippocampal pyramidal neurons. Because our hippocampal cultures are $\sim 75 \%$ glutamatergic ( $\sim 76 \%$ after estradiol exposure), a percentage of neurons may be GABAergic and express ERs, and estradiol may work to decrease GABAergic inhibition in our cultures, indirectly facilitating the increase in excitatory drive on pyramidal cells. However, because Murphy and
Segal (1996) reported that estradiol is able to produce a consistently larger effect on spine density increase than exclusive exposure to mercaptoproprionic acid, a GABA synthesis blocker, the presence of ERs on pyramidal neurons and their response to estradiol may facilitate direct processes for the formation of new spines and synapses. Moreover, GABA, traditionally thought of as the main inhibitory neurotransmitter at synapses in the adult, has been shown to have neurotrophic effects on embryonic or perinatal hippocampal neurons in culture (Berninger et al., 1995), and GABA receptor activation during brain development is a critical source of excitation. Thus, for our developing hippocampal cultures (6 d.i.v.), estradiol exposure may likely be stimulatory to GABA receptor-mediated enhanced calcium influx in developing rat hippocampal neurons (Nunez et al., 2005), prolonging the developmental duration of depolarizing GABA and promoting synaptogenesis.

\section{Extranuclear ER- $\alpha$ and ER- $\beta$ respond to estradiol with increased cluster density and colocalize with NMDARs on a subcellular level}

In our study, strong nuclear immunostaining for ERs in cultured hippocampal neurons undergoing development was present at 6 d.i.v., with punctate extranuclear immunostaining present along dendrites. The intensity of staining qualitatively varied among the neurons in our dispersion cultures. Our results corroborate previous findings that hippocampal neurons express extranuclear ER- $\alpha$ (Clarke et al., 2000; Milner et al., 2001; Adams et al., 2002; Kalita et al., 2005; Romeo et al., 2005) and extranuclear ER- $\beta$ (Mitra et al., 2003; Kalita et al., 2005; Milner et al., 2005). We focused specifically on cultured hippocampal neurons expressing the NR1 protein and analyzed the pattern and distribution of the punctate extranuclear immunostaining of ER proteins present along dendrites. These neurons responded to estradiol by significantly increasing the number of ER- $\alpha$ immunoreactive clusters along the dendrites, as detected by two different rabbit polyclonal antibodies, C1355 and MC20, corroborating recent reports (Rune et al., 2002; Romeo et al., 2005; Rune and Frotscher, 2005; Hu et al., 2007).

We also detected an increase in ER- $\beta$ protein cluster number after estradiol exposure. In vivo research reports ER- $\beta$ expression is more abundant in the hippocampus than ER- $\alpha$ (Shughrue et al., 1997) and has identified ER- $\beta$ immunoreactivity to be more extensive in extranuclear sites within dendritic spines and axon terminals than ER- $\alpha$ immunoreactivity (Milner et al., 2005). In our hands, hippocampal neurons undergoing development in vitro express similar patterns and density of both ER- $\alpha$ and ER- $\beta$ along dendrites; however, ER- $\beta$ proteins respond to estradiol exposure with greater increases in cluster density. Although extranuclear ERs respond to estradiol with an increase in density along the dendrite, we did not find evidence that estradiol drives greater association with the NMDAR in these distal sites

Because distributions of ERs change along dendrites after exposure to estradiol with an increase in cluster number of both ER- $\alpha$ and ER- $\beta$, acquisition of synapses may be regulated by the subcellular location of ERs, at the level of the individual synapse, synaptic vesicle, or bouton, rather than by total cellular expression levels as indicated by Western blot and in situ hybridization studies. Certainly, there is increasing acceptance that estradiol may act at receptors localized to the neuronal membrane surface. Previous reports detail increases in ER- $\alpha$ protein along dendrites (Hu et al., 2007) and/or decreases in ER- $\beta$ protein (Kalita et al., 2005; Rune and Frotscher, 2005; Szymczak et al., 2006) correlating to increased hippocampal synaptic function. The change in 
distribution of ERs and the colocalization with NR1 proteins in our studies suggest that local areas along the dendrite may respond to estradiol and that neural signal from estrogen and glutamate may be integrated at the subcellular level where receptors colocalize to induce synapses.

\section{The estradiol-induced increase in synapse density is mediated by ERs and reveals a critical role for ER- $\alpha$}

We hypothesized that estradiol was acting through an ERdependent mechanism and confirm that an ICI 182,780 blocked the estradiol-induced increase in synapse density along dendrites of cultured neurons. Evidence that estradiol-induced spinogenesis has been shown to be mediated in part by nuclear ERs (McEwen et al., 1999) suggests that ICI 182,780 may be antagonistic at the genomic level. However, locally regulated, nongenomic actions of estradiol by extranuclear ER may also regulate the activity of glutamatergic receptors and synapse formation. ICI 182,780 has been reported to inhibit cytoplasmic ERs as well as classic nuclear ERs (Bjornstrom and Sjoberg, 2004). However, because ICI-only-treated and control neurons do not significantly differ in synapse number along dendrites, it does not appear that endogenous estrogen production (Kretz et al., 2004; $\mathrm{Hu}$ et al., 2007), acting through ERs, contributes to the basal level of synaptogenesis in our hippocampal cultures.

PPT, an ER- $\alpha$-specific agonist, induced a significant increase in synapse number, comparable to estradiol. In contrast, an ER- $\beta$ agonist did not have a significant effect. This is in agreement with a recent report that found only the ER- $\alpha$ agonist PPT capable of inducing the same increase in spinogenesis as estradiol in specific hippocampal regions (Murakami et al., 2006). However, the role of ER- $\beta$ in synaptogenesis deserves further attention. Higher doses of DPN may very well be effective given that exposure of our cultures to DPN closely approached the arbitrary significance level of $p<0.05$ for synapse density increase and the affinity for the ER is greater for PPT than DPN, potentially making a straight mole-to-mole comparison inadequate. Recent evidence confirms that estradiol can act at the level of the synapse to activate various intracellular signaling pathways through membrane ERs. These events appear to depend on ER- $\alpha$ and ER- $\beta$ because both agonists induced ERK activation and associated NMDAR phosphorylation (Dominguez et al., 2007).

Our studies reveal that ER- $\alpha$ plays a critical functional role in hippocampal synaptogenesis. We show that (1) the estradiolinduced increase in synapse number is suppressed by ICI 182,780 and (2) an ER- $\alpha$-specific agonist induces significant increases in synapse density along dendrites comparable to estradiol. The fact that we observed increases in synapse density using an ER- $\alpha$ agonist and that both the extranuclear ER- $\alpha$ and ER- $\beta$ subtype in dendritic processes of cultured neurons are responsive to estradiol is in agreement with the theory that estradiol may work at subcellular and discrete locations along dendrites to modulate synapses. Our findings carry important implications for the role of hormonal milieu and ER expression within the developing hippocampus and further demonstrate the impact estradiol has on memory, learning, and possibly hormonemodulated neurodegeneration.

\section{References}

Adams MM, Fink SE, Shah RA, Janssen WG, Hayashi S, Milner TA, McEwen BS, Morrison JH (2002) Estrogen and aging affect the subcellular distribution of estrogen receptor- $\alpha$ in the hippocampus of female rats. J Neurosci 22:3608-3614.

Akama KT, McEwen BS (2003) Estrogen stimulates postsynaptic density-95 rapid protein synthesis via the Akt/protein kinase B pathway. J Neurosci 23:2333-2339.

Amateau SK, Alt JJ, Stamps CL, McCarthy MM (2004) Brain estradiol content in newborn rats: sex differences, regional heterogeneity, and possible de novo synthesis by the female telencephalon. Endocrinology 145:2906-2917.

Bekkers JM, Stevens CF (1989) NMDA and non-NMDA receptors are colocalized at individual excitatory synapses in cultured rat hippocampus. Nature 341:230-233.

Bellocchio EE, Hu H, Pohorille A, Chan J, Pickel VM, Edwards RH (1998) The localization of the brain-specific inorganic phosphate transporter suggests a specific presynaptic role in glutamatergic transmission. J Neurosci 18:8648-8659.

Berninger B, Marty S, Zafra F, da Penha Berzaghi M, Thoenen H, Lindholm D (1995) GABAergic stimulation switches from enhancing to repressing $\mathrm{BDNF}$ expression in rat hippocampal neurons during maturation in vitro. Development 121:2327-2335.

Bjornstrom L, Sjoberg M (2004) Estrogen receptor-dependent activation of AP-1 via non-genomic signalling. Nucl Recept 2:3.

Brose N, Huntley GW, Stern-Bach Y, Sharma G, Morrison JH, Heinemann SF (1994) Differential assembly of coexpressed glutamate receptor subunits in neurons of rat cerebral cortex. J Biol Chem 269:16780-16784.

Choi JM, Romeo RD, Brake WG, Bethea CL, Rosenwaks Z, McEwen BS (2003) Estradiol increases pre- and post-synaptic proteins in the CA1 region of the hippocampus in female rhesus macaques (Macaca mulatta). Endocrinology 144:4734-4738.

Clarke CH, Norfleet AM, Clarke MS, Watson CS, Cunningham KA, Thomas ML (2000) Perimembrane localization of the estrogen receptor alpha protein in neuronal processes of cultured hippocampal neurons. Neuroendocrinology 71:34-42.

Cline HT, Debski EA, Constantine-Paton M (1987) N-methyl-D-aspartate receptor antagonist desegregates eye-specific stripes. Proc Natl Acad Sci USA 84:4342-4345.

Crispino M, Stone DJ, Wei M, Anderson CP, Tocco G, Finch CE, Baudry M (1999) Variations of synaptotagmin I, synaptotagmin IV, and synaptophysin mRNA levels in rat hippocampus during the estrous cycle. Exp Neurol 159:574-583.

Dominguez R, Liu R, Baudry M (2007) 17-Beta-estradiol-mediated activation of extracellular-signal regulated kinase, phosphatidylinositol 3-kinase/protein kinase B-Akt and N-methyl-d-aspartate receptor phosphorylation in cortical synaptoneurosomes. J Neurochem 101:232-240.

Dubal DB, Rau SW, Shughrue PJ, Zhu H, Yu J, Cashion AB, Suzuki S, Gerhold LM, Bottner MB, Dubal SB, Merchanthaler I, Kindy MS, Wise PM (2006) Differential modulation of estrogen receptors (ERs) in ischemic brain injury: a role for ER \{alpha\} in estradiol-mediated protection against delayed cell death. Endocrinology 147:3076-3084.

Fiala JC, Feinberg M, Popov V, Harris KM (1998) Synaptogenesis via dendritic filopodia in developing hippocampal area CA1. J Neurosci $18: 8900-8911$.

Foy MR, Xu J, Xie X, Brinton RD, Thompson RF, Berger TW (1999) 17Betaestradiol enhances NMDA receptor-mediated EPSPs and long-term potentiation. J Neurophysiol 81:925-929.

Fremeau Jr RT, Troyer MD, Pahner I, Nygaard GO, Tran CH, Reimer RJ, Bellocchio EE, Fortin D, Storm-Mathisen J, Edwards RH (2001) The expression of vesicular glutamate transporters defines two classes of excitatory synapse. Neuron 31:247-260.

Gazzaley AH, Weiland NG, McEwen BS, Morrison JH (1996) Differential regulation of NMDAR1 mRNA and protein by estradiol in the rat hippocampus. J Neurosci 16:6830-6838.

Glynn MW, McAllister AK (2006) Immunocytochemistry and quantification of protein colocalization in cultured neurons. Nat Protoc 1:1287-1296.

Gomes RA, Hampton C, El-Sabeawy F, Sabo SL, McAllister AK (2006) The dynamic distribution of TrkB receptors before, during, and after synapse formation between cortical neurons. J Neurosci 26:11487-11500.

Gould E, Woolley CS, Frankfurt M, McEwen BS (1990) Gonadal steroids regulate dendritic spine density in hippocampal pyramidal cells in adulthood. J Neurosci 10:1286-1291.

Hojo Y, Hattori TA, Enami T, Furukawa A, Suzuki K, Ishii HT, Mukai H, Morrison JH, Janssen WG, Kominami S, Harada N, Kimoto T, Kawato S (2004) Adult male rat hippocampus synthesizes estradiol from preg- 
nenolone by cytochromes P45017alpha and P450 aromatase localized in neurons. Proc Natl Acad Sci USA 101:865-870.

Hu R, Cai WQ, Wu XG, Yang Z (2007) Astrocyte-derived estrogen enhances synapse formation and synaptic transmission between cultured neonatal rat cortical neurons. Neuroscience 144:1229-1240.

Kalita K, Szymczak S, Kaczmarek L (2005) Non-nuclear estrogen receptor beta and alpha in the hippocampus of male and female rats. Hippocampus 15:404-412.

Kretz O, Fester L, Wehrenberg U, Zhou L, Brauckmann S, Zhao S, PrangeKiel J, Naumann T, Jarry H, Frotscher M, Rune GM (2004) Hippocampal synapses depend on hippocampal estrogen synthesis. J Neurosci 24:5913-5921.

Leranth C, Shanabrough M, Horvath TL (2000) Hormonal regulation of hippocampal spine synapse density involves subcortical mediation. Neuroscience 101:349-356.

Luine VN, Jacome LF, Maclusky NJ (2003) Rapid enhancement of visual and place memory by estrogens in rats. Endocrinology 144:2836-2844.

McEwen B, Akama K, Alves S, Brake WG, Bulloch K, Lee S, Li C, Yuen G, Milner TA (2001) Tracking the estrogen receptor in neurons: implications for estrogen-induced synapse formation. Proc Natl Acad Sci USA 98:7093-7100.

McEwen BS, Tanapat P, Weiland NG (1999) Inhibition of dendritic spine induction on hippocampal CA1 pyramidal neurons by a nonsteroidal estrogen antagonist in female rats. Endocrinology 140:1044-1047.

Milner TA, McEwen BS, Hayashi S, Li CJ, Reagan LP, Alves SE (2001) Ultrastructural evidence that hippocampal alpha estrogen receptors are located at extranuclear sites. J Comp Neurol 429:355-371.

Milner TA, Ayoola K, Drake CT, Herrick SP, Tabori NE, McEwen BS, Warrier S, Alves SE (2005) Ultrastructural localization of estrogen receptor beta immunoreactivity in the rat hippocampal formation. J Comp Neurol 491:81-95.

Mitra SW, Hoskin E, Yudkovitz J, Pear L, Wilkinson HA, Hayashi S, Pfaff DW, Ogawa S, Rohrer SP, Schaeffer JM, McEwen BS, Alves SE (2003) Immunolocalization of estrogen receptor beta in the mouse brain: comparison with estrogen receptor alpha. Endocrinology 144:2055-2067.

Murakami G, Tsurugizawa T, Hatanaka Y, Komatsuzaki Y, Tanabe N, Mukai H, Hojo Y, Kominami S, Yamazaki T, Kimoto T, Kawato S (2006) Comparison between basal and apical dendritic spines in estrogen-induced rapid spinogenesis of CA1 principal neurons in the adult hippocampus. Biochem Biophys Res Commun 351:553-558.

Murphy DD, Segal M (1996) Regulation of dendritic spine density in cultured rat hippocampal neurons by steroid hormones. J Neurosci 16:4059-4068.

Murphy DD, Cole NB, Greenberger V, Segal M (1998) Estradiol increases dendritic spine density by reducing GABA neurotransmission in hippocampal neurons. J Neurosci 18:2550-2559.

Ni B, Rosteck Jr PR, Nadi NS, Paul SM (1994) Cloning and expression of a cDNA encoding a brain-specific $\mathrm{Na}(+)$-dependent inorganic phosphate cotransporter. Proc Natl Acad Sci USA 91:5607-5611.

Nunez JL, Bambrick LL, Krueger BK, McCarthy MM (2005) Prolongation and enhancement of gamma-aminobutyric acid receptor mediated excitation by chronic treatment with estradiol in developing rat hippocampal neurons. Eur J Neurosci 21:3251-3261.

O’Keefe JA, Handa RJ (1990) Transient elevation of estrogen receptors in the neonatal rat hippocampus. Brain Res Dev Brain Res 57:119-127.

Pozzo-Miller LD, Inoue T, Murphy DD (1999) Estradiol increases spine density and NMDA-dependent $\mathrm{Ca} 2+$ transients in spines of CA1 pyramidal neurons from hippocampal slices. J Neurophysiol 81:1404-1411.

Prange-Kiel J, Wehrenberg U, Jarry H, Rune GM (2003) Para/autocrine regulation of estrogen receptors in hippocampal neurons. Hippocampus 13:226-234.

Prange-Kiel J, Fester L, Zhou L, Lauke H, Carretero J, Rune GM (2006) Inhibition of hippocampal estrogen synthesis causes region-specific downregulation of synaptic protein expression in hippocampal neurons. Hippocampus 16:464-471.

Rao A, Craig AM (1997) Activity regulates the synaptic localization of the NMDA receptor in hippocampal neurons. Neuron 19:801-812.

Reyna-Neyra A, Arias C, Ferrera P, Morimoto S, Camacho-Arroyo I (2004) Changes in the content and distribution of microtubule associated protein 2 in the hippocampus of the rat during the estrous cycle. J Neurobiol 60:473-480.
Romeo RD, McCarthy JB, Wang A, Milner TA, McEwen BS (2005) Sex differences in hippocampal estradiol-induced $\mathrm{N}$-methyl-D-aspartic acid binding and ultrastructural localization of estrogen receptor-alpha. Neuroendocrinology 81:391-399.

Rune GM, Frotscher M (2005) Neurosteroid synthesis in the hippocampus: role in synaptic plasticity. Neuroscience 136:833-842.

Rune GM, Wehrenberg U, Prange-Kiel J, Zhou L, Adelmann G, Frotscher M (2002) Estrogen up-regulates estrogen receptor alpha and synaptophysin in slice cultures of rat hippocampus. Neuroscience 113:167-175.

Sabo SL, McAllister AK (2003) Mobility and cycling of synaptic proteincontaining vesicles in axonal growth cone filopodia. Nat Neurosci 6:1264-1269.

Sandstrom NJ, Williams CL (2004) Spatial memory retention is enhanced by acute and continuous estradiol replacement. Horm Behav 45:128-135.

Shah RD, Anderson KL, Rapoport M, Ferreira A (2003) Estrogen-induced changes in the microtubular system correlate with a decreased susceptibility of aging neurons to beta amyloid neurotoxicity. Mol Cell Neurosci 24:503-516.

Shughrue PJ, Lane MV, Merchenthaler I (1997) Comparative distribution of estrogen receptor-alpha and -beta mRNA in the rat central nervous system. J Comp Neurol 388:507-525.

Siegel SJ, Brose N, Janssen WG, Gasic GP, Jahn R, Heinemann SF, Morrison JH (1994) Regional, cellular, and ultrastructural distribution of $\mathrm{N}$-methyl-D-aspartate receptor subunit 1 in monkey hippocampus. Proc Natl Acad Sci USA 91:564-568.

Smith CC, McMahon LL (2005) Estrogen-induced increase in the magnitude of long-term potentiation occurs only when the ratio of NMDA transmission to AMPA transmission is increased. J Neurosci 25:7780-7791.

Solum DT, Handa RJ (2001) Localization of estrogen receptor alpha (ER alpha) in pyramidal neurons of the developing rat hippocampus. Brain Res Dev Brain Res 128:165-175.

Suzuki S, Brown CM, Dela Cruz CD, Yang E, Bridwell DA, Wise PM (2007) Timing of estrogen therapy after ovariectomy dictates the efficacy of its neuroprotective and antiinflammatory actions. Proc Natl Acad Sci USA 104:6013-6018.

Szymczak S, Kalita K, Jaworski J, Mioduszewska B, Savonenko A, Markowska A, Merchenthaler I, Kaczmarek L (2006) Increased estrogen receptor beta expression correlates with decreased spine formation in the rat hippocampus. Hippocampus 16:453-463.

Tovar KR, Westbrook GL (2002) Mobile NMDA receptors at hippocampal synapses. Neuron 34:255-264.

Washbourne P, Bennett JE, McAllister AK (2002) Rapid recruitment of NMDA receptor transport packets to nascent synapses. Nat Neurosci 5:751-759.

Washbourne P, Liu XB, Jones EG, McAllister AK (2004) Cycling of NMDA receptors during trafficking in neurons before synapse formation. J Neurosci 24:8253-8264.

Weiland NG (1992) Estradiol selectively regulates agonist binding sites on the N-methyl-D-aspartate receptor complex in the CA1 region of the hippocampus. Endocrinology 131:662-668.

Woolley CS, McEwen BS (1992) Estradiol mediates fluctuation in hippocampal synapse density during the estrous cycle in the adult rat. J Neurosci 12:2549-2554.

Woolley CS, McEwen BS (1993) Roles of estradiol and progesterone in regulation of hippocampal dendritic spine density during the estrous cycle in the rat. J Comp Neurol 336:293-306.

Woolley CS, McEwen BS (1994) Estradiol regulates hippocampal dendritic spine density via an $N$-methyl-D-aspartate receptor-dependent mechanism. J Neurosci 14:7680-7687.

Woolley CS, Wenzel HJ, Schwartzkroin PA (1996) Estradiol increases the frequency of multiple synapse boutons in the hippocampal CA1 region of the adult female rat. J Comp Neurol 373:108-117.

Woolley CS, Weiland NG, McEwen BS, Schwartzkroin PA (1997) Estradiol increases the sensitivity of hippocampal CA1 pyramidal cells to NMDA receptor-mediated synaptic input: correlation with dendritic spine density. J Neurosci 17:1848-1859.

Yankova M, Hart SA, Woolley CS (2001) Estrogen increases synaptic connectivity between single presynaptic inputs and multiple postsynaptic CA1 pyramidal cells: a serial electron-microscopic study. Proc Natl Acad Sci USA 98:3525-3530. 